\title{
Assessment of soil nematode diversity based on different taxonomic levels and functional groups
}

\author{
Jiangnan $\mathrm{Li}^{1,2}$, Peiqin Peng ${ }^{2}$, Jie Zhao ${ }^{1,3, *}$ \\ 1 Key Laboratory of Agro-ecological Processes in Subtropical Region, Institute of Subtropical Agriculture, Chinese Academy of Sciences, \\ Changsha 410125, China \\ 2 College of Environmental Science and Engineering, Central South University of Forestry and Technology, Changsha 410004, China \\ 3 Huanjiang Observation and Research Station for Karst Ecosystems, Chinese Academy of Sciences, Huanjiang 547100, China
}

\section{ARTICLE INFO}

Article history:

Received August 22, 2019

Revised October 6, 2019

Accepted October 22, 2019

\section{Keywords:}

Biodiversity

Soil nematodes

Taxon diversity

Functional group diversity

Indicator

\begin{abstract}
A B S T R A C T
Although soil nematode diversity has been used as an indicator of habitat characteristics and environmental change, the diversity of entire soil nematode communities has not been comprehensively evaluated at different taxonomic levels, or for different functional groups, or at a fine taxonomic level within functional groups. In this study, two taxonomic diversity indices, the Shannon-Wiener index $\left(\mathrm{H}^{\prime}\right)$ and Simpson index $(\lambda)$, were used to evaluate the following: 1) nematode diversity at different taxonomic levels for the whole community, 2) nematode diversity of different functional groups, and 3 ) nematode generic diversity of functional groups in the following four land-use types: forage land, cropland, secondary forest, and grassshrubland. The results showed that significant differences in nematode diversity among landuse types were detected by assessment at the order level but not at the family or genus level. The results also showed that significant differences in nematode diversity were better revealed by assessment of trophic groups rather than $c p$ groups. The generic diversities $\left(\mathrm{H}^{\prime}\right)$ of omnivorous nematodes and $c p 3$ nematodes also significantly differed among land-use types. Our results indicate that diversity at a high taxonomic level (i.e., order) may be a more useful indicator than diversity at a low taxonomic level (i.e., family or genus) of differences among land-use types. In addition, the functional group diversity (i.e., trophic group, $c p$ group, and the combination of these two groups) for the whole community and the taxonomic diversity within functional groups were useful indicators of differences among land-use types.
\end{abstract}

(c) Higher Education Press 2019

\section{Inroduction}

Nematodes are abundant soil animals that affect many important ecosystems processes (Freckman and Caswell, 1985; Bongers and Ferris, 1999; Ferris et al., 2001). The diversity of soil nematodes can differ greatly among ecosys-

\footnotetext{
* Corresponding author

E-mail address: jzhao@isa.ac.cn (J. Zhao)
}

tems (Boag and Yeates, 1998; Nielsen et al., 2014; Song et al., 2017), and assessment of nematode diversity has become an important research area in soil ecology. Nematode diversity can reflect soil biodiversity, soil resource diversity, and resource utilization diversity, and can serve as a useful indicator of the nutrient status of the ecosystem and the structure of the soil food web (Neher and Barbercheck, 1998; Ferris et al., 2001; Ferris et al., 2012; Ferris and Tuomisto, 2015). A useful indicator should have the function of reflecting and predicting ecosystems processes accurately. However, 
the relationship between ecosystems processes and diversity is unclear, most nematode communities have a lack of understanding, and a single community diversity index cannot clearly describe the ecosystems processes (Neher and Darby, 2009). Most recent assessments of nematode communities have not been based on taxon diversity but instead have focused on the use of nematode faunal indices, such as the maturity index, structure index, enrichment index, channel index, and metabolic footprint index (Bhusal et al., 2014).

Nematodes can be classified at different taxonomic levels (order, family, genus, and species) and can also be assigned to different functional groups (Bongers and Bongers, 1998; Ferris et al., 2001; Yeates, 2003). Because most previous studies have identified nematodes to the genus level, nematodes taxomic diversity generally refers to generic diversity. However, nematode genera vary in their responses to ecological disturbances, which could cause nematode faunal indices to incorrectly indicate responses to disturbances (Fiscus and Neher, 2002; Zhao and Neher, 2013). In addition, whether species-level designations are necessary in ecological studies has been debated. Some researchers have argued that species-level designations are too costly and time consumming (Boag and Yeates, 1998; Pik et al., 1999; Terlizzi et al., 2003). Consistent with this view, Bhusal et al. (2014) reported that taxonomic identification at both a low level (genus) and a high level (order or family) can reliablely indicate nematode diversity in different habitats. However, assessments of nematode diversity based on nematode order, family, genus, feeding group and/or functional guild have not been comprehensively compared, nor has the generic diversity for different feeding groups and functional guilds been comprehensively analyzed (Bhusal et al., 2014). In addition, it is unclear whether the nematode faunal indices or the diveristy indices are better predictors for distinguishing significnat diffences in nematode communities of different ecosystems or under different disturbance types.

The Shannon-Wiener index $\left(\mathrm{H}^{\prime}\right)$ and the Simpson index $(\lambda)$ are commonly used to describe the taxonomic diversity of soil nematodes (Yeats and Bongers, 1999; Neher and Darby, 2009). The Shannon-Wiener index gives more weight to rare species, and the Simpson dominance index gives more weight to dominant species (Neher and Darby, 2009; Zhao et al., 2014). The current study used both of these indices to evaluate the following for the whole nematode community: 1) nematode diversity at different taxonomic levels (e.g., order, family, and genus) for the whole community, 2) nematode diversity of different functional groups (e.g., trophic groups and/or colonizer-persister [cp] groups), and 3) nematode generic diversity of functional groups in the following four landuse types: forage land, cropland, secondary forest, and grassshrubland. The objectives were to determine whether the analysis of nematode biodiversity requires fine-level designations to detect environmental differences associated with land-use differences and whether the generic diversity for a given nematode functional group reflects environmental differences.

\section{Methods}

\subsection{Data collection}

The data used in this research were obtained from a study that assessed soil nematode abundance and generic composition in four land-use types in south-west China. Detailed information about the study and the study sites was provided by Zhao et al. (2015). In brief, the study was conducted at Huanjiang Observation and Research Station for Karst Ecosystems $\left(107^{\circ} 51^{\prime}-108^{\circ} 43^{\prime} \mathrm{E}, 24^{\circ} 44^{\prime}-25^{\circ} 33^{\prime} \mathrm{N}\right)$, Chinese Academy of Sciences (CAS), Guangxi Province, China. The four land-use types were forage land, cropland, secondary forest, and grass-shrubland. Each land-use type was represented by four replicate sites. All sites had a brown calcareous soil that developed from a dolostone base.

\subsection{Data analysis}

To determine the effects of taxonomic level on the assessment of diversity, the nematode genera were assigned to families and orders. Although assignments to nematode trophic group and life history strategy (also known as the colonizer-persister [cp] scale) are mainly based on generic and family identifications (Yeates et al., 1993; Bongers and Bongers, 1998), diversity based on trophic group or $c p$ group may be different from diversity based on genus, family, and order. In addition, the generic diversity may differ among trophic groups or $c p$ groups, and the generic diversity of trophic groups or $c p$ groups may differ from the generic diversity of the whole nematode community. Therefore, nematodes were assigned to five trophic groups (i.e., bacterivore, fungivore, herbivore, omnivore, and predator) according to Yeates et al. (1993) and Okada et al. (2005), to five cp groups (i.e., $c p 1-5$ ) according to Bongers and Bongers (1998), and to 16 functional guilds (i.e., a combination of trophic group and $c p$ group: Ba1-4, Fu2-4, He2-5, Om4-5, and Pr3-5). The Shannon-Wiener index $\left(\mathrm{H}^{\prime}\right)$ and the Simpson index $(\lambda)$ were calculated for various classification levels and different groups as follows:

$$
\begin{gathered}
\text { Shannon-Wiener index, } \mathrm{H}^{\prime}=-\sum_{i=1}^{s} P i * \ln P i \\
\text { Simpson index, } \lambda=\Sigma P i^{2}
\end{gathered}
$$

where ' $P i$ ' is the proportion of the individuals of " $i$ th" taxon in a nematode assemblage, and ' $s$ ' is the total number of nematode taxa in the given assemblage.

Before analysis, data were $\log (x+1)$ transformed when required to improve normality and homogeneity of variance. One-way ANOVAs were used to examine differences in nematode diversity among the four land-use types. When ANOVAs were significant $(p<0.05)$, LSD was used to test for difference among land-use types. Tamhane's T2 was used to test for differences among land-use types when the variances of transformed data were not equal. The one-way ANOVAs were performed using SPSS24 software (SPSS Inc., Chicago, IL). 


\section{Results}

3.1 Diversity indices for the whole nematode communities at different taxonomic levels and of different functional groups

The patterns of nematode generic diversity and family diversity as indicated by either $\mathrm{H}^{\prime}$ or $\lambda$ did not significantly differ among the four land-use types (Fig. 1A,B and Fig. 2A,B). At the order level, $\mathrm{H}^{\prime}$ was significantly lower for the cropland than for the secondary forest or grass-shrubland (Fig. 1C) but did not significantly differ among the forage land, secondary forest, and grass-shrubland (Fig. 1C). At the order level, $\lambda$ was significantly higher for the cropland than for secondary forest (Fig. 2C) but did not significantly differ between cropland/ secondary forest and forage land/grass-shrubland (Fig. 2C). For trophic groups, $\mathrm{H}^{\prime}$ did not significantly differ among the four land-use types (Fig. 1D). For trophic groups, $\lambda$ was significantly higher for the grass-shrubland than for the secondary forest (Fig. 2D). For $c p$ groups, neither $\mathrm{H}^{\prime}$ nor $\lambda$ significantly differed among the four land-use types (Fig. 1E and $2 \mathrm{E}$ ). At the functional guild level, $\mathrm{H}^{\prime}$ was significantly lower for the cropland than for the grass-shrubland but did not significantly differ between the forage land and the secondary forest (Fig. 1F). At the functional guild level, $\lambda$ did not significantly differ among the four land-use types (Fig. 2F).

3.2 Diversity indices for genus composition of nematode functional groups

For the generic diversity of bacterivores, fungivores, herbivores, and predators, neither $\mathrm{H}^{\prime}$ nor $\lambda$ significantly differed among the four land-use types (Fig. 3 A,B,C,E and Fig. 4 A,B, $\mathrm{C}, \mathrm{E})$. For the generic diversity of the omnivores, $\mathrm{H}^{\prime}$ was significantly higher for the grass-shrubland than for forage land or secondary forest (Fig. 3D) but did not significantly differ among the forage land, cropland, and secondary forest (Fig. 3D). For the generic diversity of the omnivores, $\lambda$ was significantly higher for the secondary forest than for the cropland or grass-shrubland (Fig. 4D) but did not significantly differ among the forage land, cropland, and grass-shrubland (Fig. 4D). Values of $\lambda$ of the $c p 1$ group did not significantly differ among the four land-use types (Fig. 4F). Neither $\mathrm{H}^{\prime}$ nor $\lambda$ of the $c p 2$ group significantly differed among the four land-use types (Fig. 3F and Fig. 4G). For the cp3 group, $\mathrm{H}^{\prime}$ was significantly higher for the grass-shrubland than for the forage land (Fig. 3G) but did not significantly differ among cropland, secondary forest, and grass-shrubland (Fig. 3G). Values of $\lambda$ for the cp3 group did not significantly differ among the four land-use types (Fig. $4 \mathrm{H}$ ). As indicated by either $\mathrm{H}^{\prime}$ or $\lambda$, the generic diversity for the $c p 4$ group and the $c p 5$ group did not significantly differ among land-use types (Fig. $3 \mathrm{H}, \mathrm{I}$ and Fig. 4 I,J).

\section{Discussion}

We found that the diversity at the order level was more sensitive to land-use types than diversity at the family or genus level, indicating that assessment of lower taxonomic levels is not always better than assessment at higher levels at reflecting land-use effects. Additionally, the patterns of the nematode generic diversity and family diversity were basically
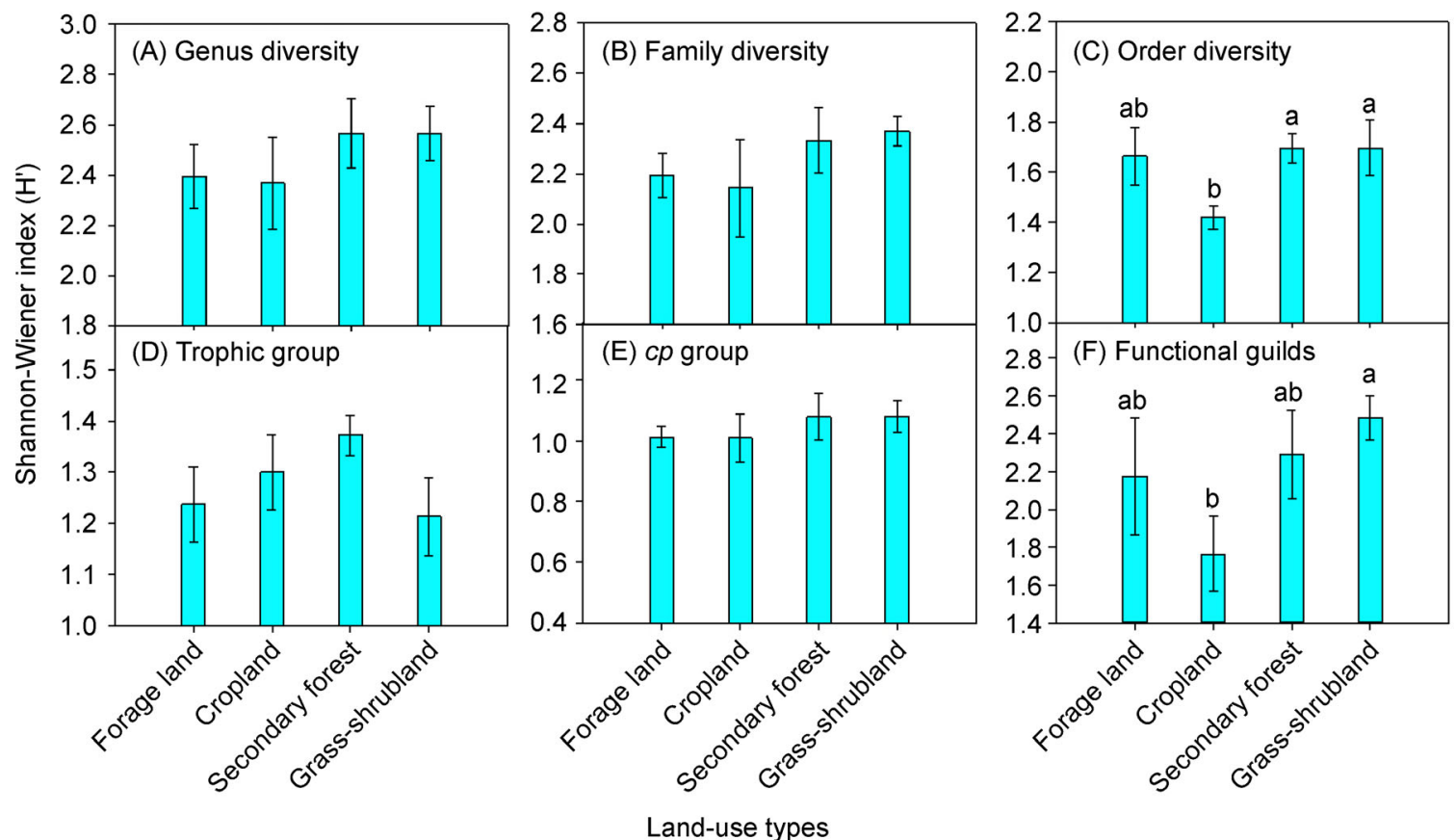

Fig. 1 The Shannon-Wiener index $\left(\mathrm{H}^{\prime}\right)$ of the whole nematode community at the level of genus (A), family (B), order (C), trophic group (D), $c p$ group $(E)$, and functional guild $(F)$ in the forage land, cropland, secondary forest, and grass-shrubland. Values are means $\pm S E$. Different letters indicate significant $(p<0.05)$ differences among land-use types. 

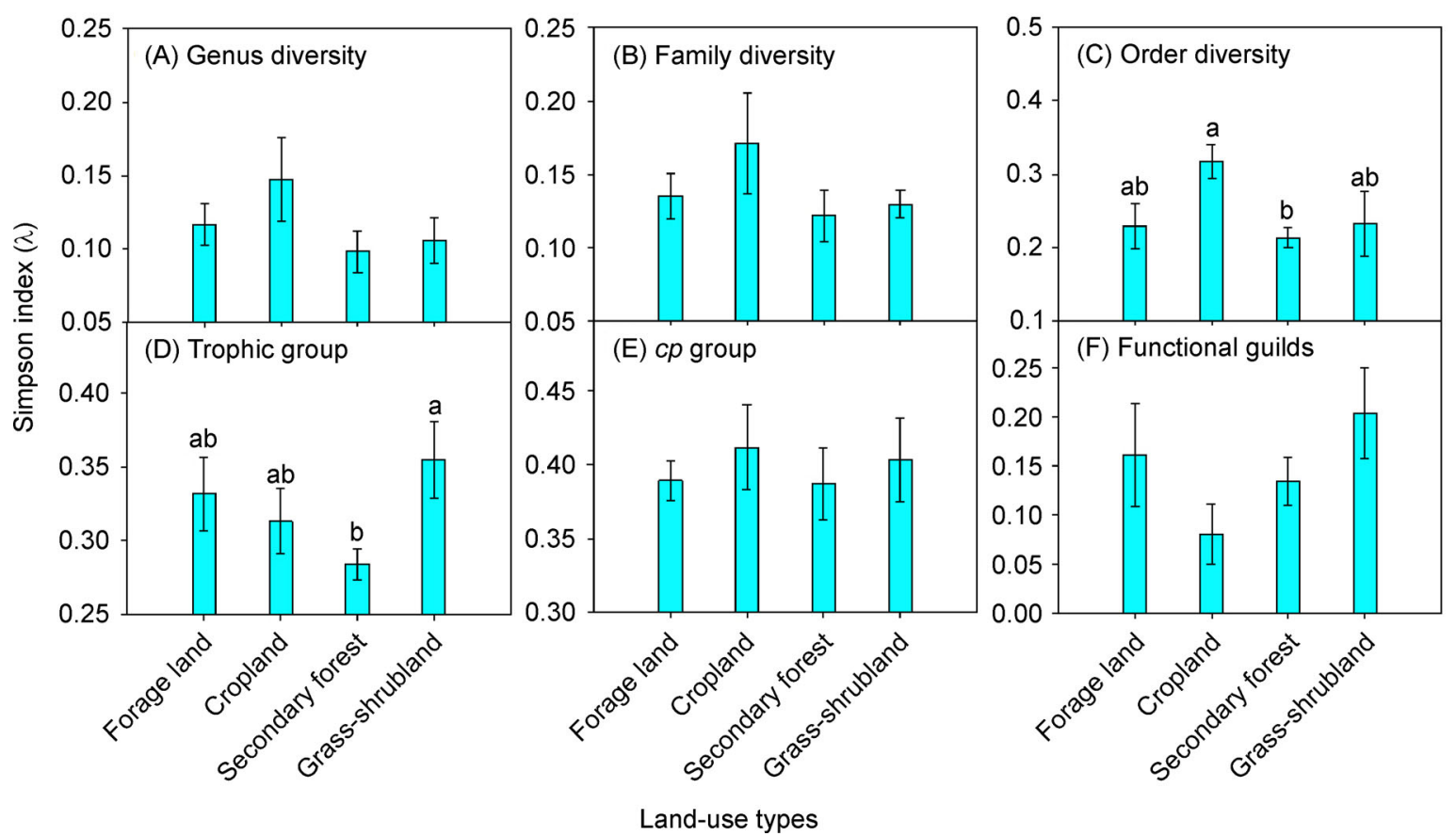

Fig. 2 The Simpson index $(\lambda)$ of the whole nematode community at the level of genus (A), family (B), order (C), trophic group (D), $c p$ group $(E)$, and functional guild $(F)$ in the forage land, cropland, secondary forest, and grass-shrubland. Values are means $\pm S E$. Different letters indicate significant $(p<0.05)$ differences among land-use types.

the same, which was consistent with previous reports (Bhusal et al., 2014). The inconsistent responses of order, family, and genus diversity to land-use types can probably be explained by taxon number. Although only $18 \%$ of the taxonomic units were reduced after assigning nematode genera to their corresponding families, $60 \%$ of the taxonomic units were reduced after assigning nematode genera to their corresponding orders. It follows that the weights of taxa (their effects on diversity assessment) did not differ between assessments of genera and families but were substantially increased for assessments of orders vs. assessments of genera and families. Whether this effect of taxon level on taxon weight is a common phenomonen warrants further study.

The patterns of the diversities differed for nematode trophic groups, $c p$ groups, and functional guilds. In particular, trophic group diversity was more sensitive to land-use types than $c p$ group diversity. This finding is consistent with Bhusal et al. (2014), who reported that trophic diversity could be used as a reliable indicator of the effects of environment on diversity (Bhusal et al., 2014). In addition, the functional guild diversity as indicated by the Shannon-Weiner index significantly differed among land-use types. The latter finding indicates that diversity at higher classification levels may be inferior to the diversity of functional groups in reflecting the characteristics of different ecosystems or land-use types. Soil nematodes feed on various food resources and occupy several trophic levels in the soil food web (Yeates et al., 1993; Ferris et al., 2001). The environments and food resources generally differ among ecosystems. Therefore, nematode functional group composition (i.e., the diversity-weighted abundance) may reflect the diversity and/or heterogeneity of resources and environments (Ferris and Tuomisto, 2015).

For the five trophic groups and the five $c p$ groups, only the generic diversity of omnivores and of $c p 3$ nematodes significantly differed among land-use types. Omnivorous nematodes feed on diverse food resources, which affect other soil organisms (including other nematodes) and may reflect the biodiversity and diversity of soil food resources (Ferris and Tuomisto, 2015; Song et al., 2017). The nematodes in the $c p 3$ group are relatively sensitive to disturbances (Bongers and Bongers, 1998). Therefore, disturbance may be one of the factors affecting the distribution of nematodes in different land-use types; cropland fertilization, for example, reduced the numbers of omnivorous nematodes (Neher and Barbercheck, 1998). In the current study, the grass-shrubland had developed with little anthropogenic disturbance for more than 20 years and had substantial plant diversity that provided diverse food resources for soil organisms (Zhao et al., 2015). This suggests that diverse food resources and an undisturbed environment may be conducive to omnivorous and $c p 3$ nematodes. Therefore, the taxon diversity within each functional group may also be a good indicator of soil biodiversity, soil resource diversity, and ecosystem disturbance.

As noted above, diversity assessment in different taxonomic levels and for different groups revealed significant effects of land-use types on soil nematode communities and could be served as good indicators. Surprisingly, however, the commonly used nematode faunal indices had no significant difference among the four land-use types except the plant- 

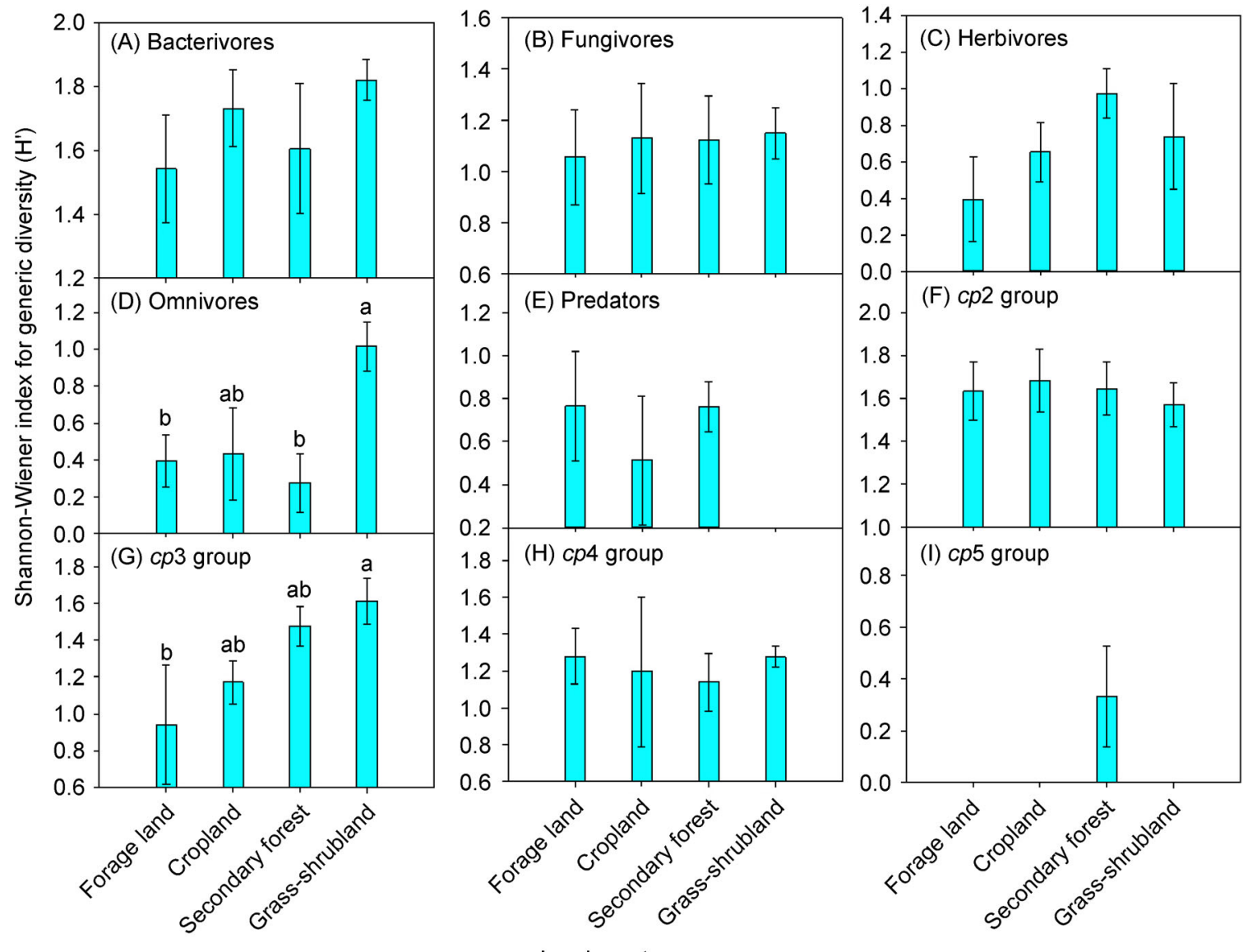

Fig. 3 The Shannon-Wiener index $\left(H^{\prime}\right)$ for the generic diversity of the bacterivores (A), fungivores (B), herbivores (C), omnivores (D), predators $(\mathrm{E}), c p 2$ group $(\mathrm{F}), c p 3$ group $(\mathrm{G}), c p 4$ group $(\mathrm{H})$, and $c p 5$ group $(\mathrm{I})$ in the forage land, cropland, secondary forest, and grassshrubland. Values are means \pm SE. Different letters indicate significant $(p<0.05)$ differences among land-use types.

parasite index (Supporting information, Table S1). Particularly, the plant-parasite index was apparent higher in the grassshrubland than those in the other three land-use types (Supporting information, Table S1). Therefore, comprehensive assessments of the nematode diversity in different taxonomic levels and for different groups may provide important information that could not revealed by the nematode faunal assessments. The diversity indices is mainly based on analysis of relative abundance taxa and/or the number of taxa (Yeates, 1984; Yeats and Bongers, 1999), while the faunal indices is mainly based on analysis of relative abundance taxa and life history strategies (i.e. feeding types and $c p$ values for nematodes) (Bongers and Ferris, 1999; Ferris et al., 2001). Since nematode life history strategies quantified, we think the basis of the diversity indices and faunal indices may be similar and both of them could reflect the nematode community compositions. Indeed, a single community diversity index cannot clearly describe the ecosystem properties (Neher and Darby, 2009). But a series of diversity indices calculated for different groups and/or in different taxonomic levels may be better in revealing the ecosystem properties. Future studies could further help determine whether the diversity indices are better indicators than the faunal indices.

In addition, data variance, as indicted by the error bar, was high for each variable in each land-use type in this study. Especially, the variances of generic diversity in predators were larger than those in bacterivores, fungivores, herbivores and omnivores, and in $c p 4$ and $c p 5$ groups were larger than those in $c p 2$ and $c p 3$ groups. The most likely reason for the high variances of generic diversity in predators, $c p 4$ and $c p 5$ groups is that the abundances of nematode genera in these groups are very low and may be undetectable. Number of replications is an important factor determined the data variance (Chalcraft, 2019). The larger the number of replications, the smaller the data variance. Furthermore, the statistical rule cannot be revealed if the replication number is too small (Li et al., 2000; Shao et al., 2009). We believe that more replications are conducive to reduce the variances of data and may help to reveal more information. However, increasing replications will increase the time and resource investment in nematode identification. Therefore, a reasonable replication number should be considered for given studies based on a tradeoff between potential performance improvement of statistical analysis and time and resource 

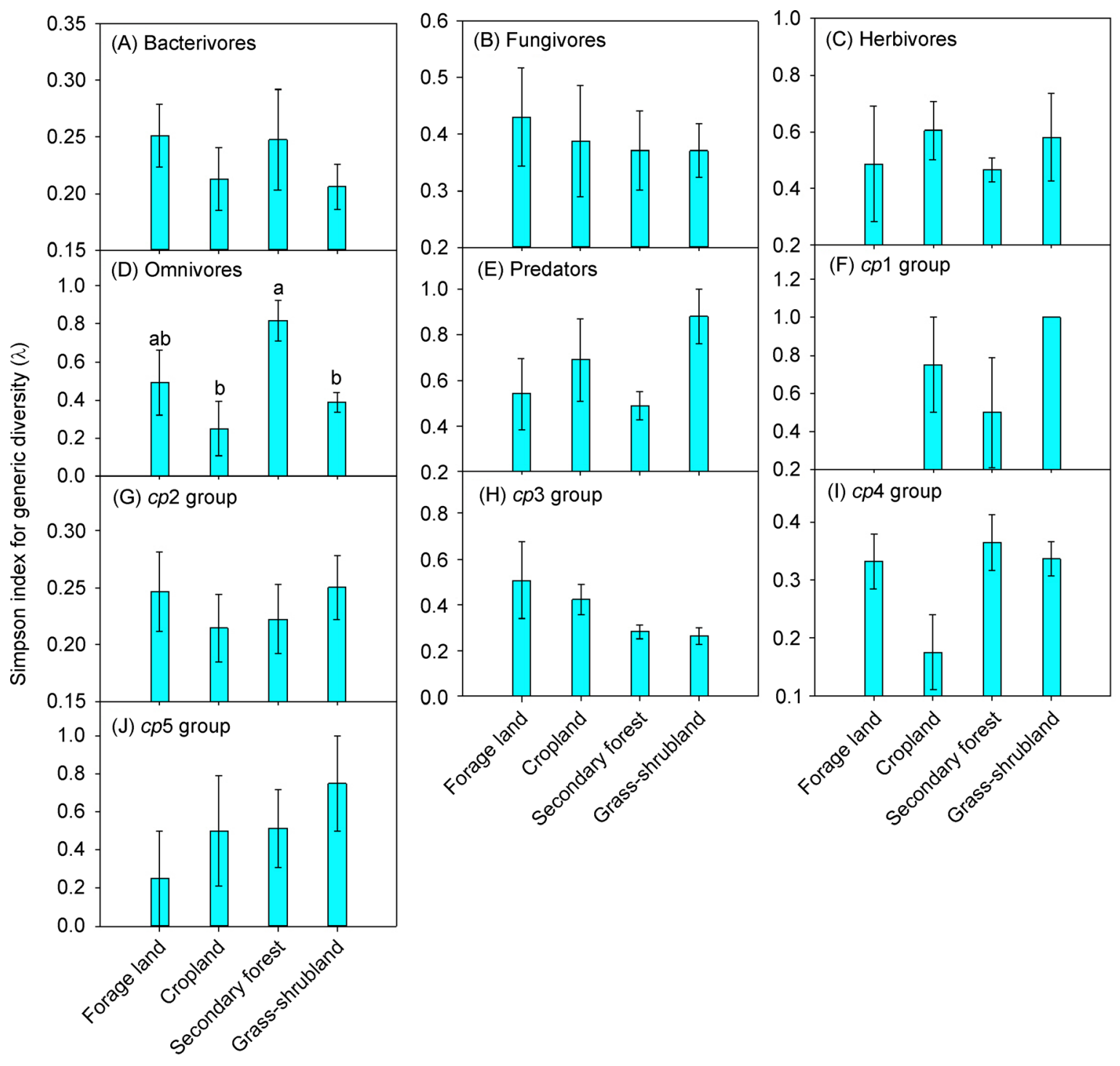

Land-use types

Fig. 4 The Simpson index $(\lambda)$ for the generic diversity of the bacterivores $(A)$, fungivores $(B)$, herbivores $(C)$, omnivores $(D)$, predators $(E)$, $c p 1$ group $(F), c p 2$ group $(\mathrm{G})$, cp3 group $(\mathrm{H}), c p 4$ group $(\mathrm{I})$, and $c p 5$ group $(\mathrm{J})$ in the forage land, cropland, secondary forest and grassshrubland. Values are means \pm SE. Different letters indicate significant $(p<0.05)$ differences among land-use types.

investment in traditional nematode microscopy identification. In addition, application of new methods (e.g., molecular methods) to evaluate the diversity of soil nematodes will greatly improve the time efficiency of the nematode community analysis and may make larger sample size accessible (Porazinska et al., 2009; Darby et al., 2013). However, the molecular identification of nematodes is not mature and application of molecular techniques to nematode community analysis needs to be further tested.

\section{Conclusion}

In summary, assessment of nematode diversity at a high classification level (i.e., order) was more sensitive at detecting differences among land-use types than assessment of nematode diversity at a low classification level (i.e., genus and family). In addition, the functional group diversity and the taxon diversity for each functional group of nematodes revealed significant differences among land-use types. A basic ranking of nematode diversity for the four land-use types in this study was cropland < forage land < secondary forest $<$ grass-shrubland, which was consistent with the disturbance intensities of these land-use types (Zhao et al., 2015). In other words, disturbance decreased nematode diversity. The results indicate that ecological studies of soil nematode diversity may benefit from systematically analyzing 1) nematode diversity at different classification levels, 2) the diversity of different functional groups of nematodes, and 3) taxon diversity within each functional group of nematodes. 


\section{Confict of interest}

Jiangnan Li, Peiqin Peng and Jie Zhao declare that they have no conflict of interest.

\section{Acknowledgments}

We thank Prof. Bruce Jaffee for his help in preparing the manuscript. This study was supported by the National Natural Science Foundation of China (41877055); the National Key Technology Research and Development Program of the Ministry of Science and Technology of China (2016YFC0502400); the Guangxi Natural Science Foundation Program (2018GXNSFAA2 81008); the Foundation for Young Scholars in Western China of CAS given to Jie Zhao; and the Youth Innovation Team Project of ISA, CAS (2017QNCXTD_ZJ).

\section{References}

Bhusal, D.R., Kallimanis, A.S., Tsiafouli, M.A., Sgardelis, S.P., 2014. Higher taxa vs. functional guilds vs. trophic groups as indicators of soil nematode diversity and community structure. Ecological Indicators 41, 25-29.

Boag, B., Yeates, G., 1998. Soil nematode biodiversity in terrestrial ecosystems. Biodiversity and Conservation 7, 617-630.

Bongers, T., Bongers, M., 1998. Functional diversity of nematodes. Applied Soil Ecology 10, 239-251.

Bongers, T., Ferris, H., 1999. Nematode community structure as a bioindicator in environmental monitoring. Trends in Ecology \& Evolution 14, 224-228.

Chalcraft, D.R., 2019. To replicate, or not to replicate- that should not be a question. Ecology Letters 22, 1174-1175.

Darby, B.J., Todd, T.C., Herman, M.A., 2013. High-throughput amplicon sequencing of rRNA genes requires a copy number correction to accurately reflect the effects of management practices on soil nematode community structure. Molecular Ecology 22, 5456-5471.

Ferris, H., Bongers, T., Goe, R.G.M., 2001. A framework for soil food web diagnostics: extension of the nematode faunal analysis concept. Applied Soil Ecology 18, 13-29.

Ferris, H., Griffiths, B.S., Porazinska, D.L., Powers, T.O., Wang, K.H. Tenuta, M., 2012. Reflections on plant and soil nematode ecology: past, present and future. Journal of Nematology 44, 115-126.

Ferris, H., Tuomisto, H., 2015. Unearthing the role of biological diversity in soil health. Soil Biology \& Biochemistry 85, 101-109.

Fiscus, D.A., Neher, D.A., 2002. Distinguishing sensitivity of free-living soil nematode genera to physical and chemical disturbances. Ecological Applications 12, 565-575.

Freckman, D.W., Caswell, E.P., 1985. The ecology of nematodes in agroecosystems. Annual Review of Phytopathology 23, 275-296.

Li, S., Gao, Y., Li, S., 2000. Study on spatial variability of soil nutrient and determining number of sample. Turang Yu Huanjing 9, 56-59.

Neher, D., Barbercheck, M., 1998. Diversity and Function of Soil Mesofauna. Biodiversity in Agroecosystems.

Neher, D.A., Darby, B.J., 2009. General community indices that can be used for analysis of nematode assemblages. Nematodes as Environmental Indicators, 107-123.

Nielsen, U.N., Ayres, E., Wall, D.H., Li, G., Bardgett, R.D., Wu, T., Garey, J.R., 2014. Global-scale patterns of assemblage structure of soil nematodes in relation to climate and ecosystem properties. Global Ecology and Biogeography 23, 968-978.

Okada, H., Araki, M., Tsukiboshi, T., Harada, H., 2005. Characteristics of Tylencholaimus parvus (Nematoda: Dorylaimida) as a fungivorus nematode. Nematology 7, 843-849.

Pik, A.J., Oliver, I., Beattie, A.J., 1999. Taxonomic sufficiency in ecological studies of terrestrial invertebrates. Australian Journal of Ecology 24, 555-562.

Porazinska, D.L., Giblin-Davis, R.M., Faller, L., Farmerie, W., Kanzaki, N., Morris, K., Powers, T.O., Tucker, A.E., Sung, W., Thomas, W. $\mathrm{K}$., 2009. Evaluating high-throughput sequencing as a method for metagenomic analysis of nematode diversity. Molecular Ecology Resources 9, 1439-1450.

Shao, H., Tian, J., Guo, K., Sun, J., 2009. Effects of sample size and species traits on performance of bioclim in predicting geographical distribution of tree species - a case study with 12 deciduous quercus species indigenous to china. Acta Phytoecologica Sinica 33, 870-877.

Song, D., Pan, K., Tariq, A., Sun, F., Li, Z., Sun, X., Zhang, L., Olusanya, O.A., Wu, X., 2017. Large-scale patterns of distribution and diversity of terrestrial nematodes. Applied Soil Ecology 114, 161-169.

Terlizzi, A., Bevilacqua, S., Fraschetti, S., Boero, F., 2003. Taxonomic sufficiency and the increasing insufficiency of taxonomic expertise. Marine Pollution Bulletin 46, 556-561.

Yeates, G.W., 1984. Variation in soil nematode diversity under pasture with soil and year. Soil Eiol. Biochem. 16, 95-102.

Yeates, G.W., 2003. Nematodes as soil indicators: functional and biodiversity aspects. Biology and Fertility of Soils 37, 199-210.

Yeates, G.W., Bongers, T., De Goede, R.G., Freckman, D.W., Georgieva, S.S., 1993. Feeding habits in soil nematode families and genera - an outline for soil ecologists. Journal of Nematology 25, 315-331.

Yeats, G.W., Bongers, T., 1999. Nematode diversity in agroecosystems. Agriculture, Ecosystems \& Environment 74, 113-135.

Zhao, J., Neher, D.A., 2013. Soil nematode genera that predict specific types of disturbance. Applied Soil Ecology 64, 135-141.

Zhao, J., Wan, S., Zhang, C., Liu, Z., Zhou, L., Fu, S., 2014. Contributions of understory and/or overstory vegetations to soil microbial PLFA and nematode diversities in Eucalyptus monocultures. PLoS One 9, e85513.

Zhao, J., Xun, R., He, X., Zhang, W., Fu, W., Wang, K., 2015. Size spectra of soil nematode assemblages under different land-use types. Soil Biology \& Biochemistry 85, 130-136. 